\title{
Sobre a Dosagem Fotométrica do Cobre em Águas
}

\author{
Reinaldo Spitzner \\ Instituto de Biologia e Pesquisas Tecnológicas
}

\begin{abstract}
The author presents an analytic process for copper quantitative determination in mineral and potable waters, based in the reaction of the cation copper with sodium diethyl-dithio carbamate. Due to the presence of certain elements common in water, such as iron, calcium, magnesium, etc., the main principles of the reactions behavior were studied. In the same manner the reaction sensibility was verified, as well as its precision, by the addition of known quantities of copper. About the end of the work presented, there are shown some copper determinations made through the mentioned process with mineral and potable waters of Paraná.
\end{abstract}

Key Words: Copper; photometry; mineral waters

\section{INTRODUÇÃO}

O cobre há muito foi reconhecido como elemento de incontestável valor à vida.

Modernamente, ficou perfeitamente conhecida a função que o cobre desempenha nas atividades fisiológicas da hemoglobina, a qual sendo rica em ferro, necessita o estímulo catalítico de vestígios de cobre, que o sangue deve normalmente conter.

SARZEAU (1830), tendo encontrado o cobre em todas as plantas por ele analisadas, considerou esse elemento como normal nas plantas, tendo BERTRAND (1920) e CHEVREUL (1868), chegado às mesmas conclusões.

MILLON (1848), constatou a presença de cobre nas cinzas do sangue, na proporção que variou de 0,5 a $2,5 \%$.

Pelos trabalhos de LECHARTIER e BAILLY, citados por ACHARD (1877), foram novamente confirmadas as observações de MILLON (1848), cabendo a BERGERON e D'HOTE a verificação da presença do cobre no fígado e rins humanos.
SCHONHEIMER e OSHIMA, em 1927, encontraram para a dose normal de cobre no fígado do homem, uma quantidade que varia de 3 a 9 miligramas por quilo.

WADDEL e HART (1929) demonstraram a especificidade do cobre no tratamento das ratas anemiadas, sendo de anotar que nesse mesmo trabalho, o zinco, o cromo, o níquel e o chumbo foram experimentados, com resultados nulos.

Quando às ratas anemiadas se lhe incorpora somente o ferro, pouco ou nada influi na cura dessa anemia; ao revés, quando traços de cobre são adicionados ao ferro ministrado, é notada uma cura rápida e eficiente.

FLINN e INOUGE (1929), estudando acuradamente a ação do cobre no organismo, evidenciaram que pelo seu concurso, há aumento da "capacidade respiratória" do sangue nos animais que receberam o cobre como suplemento à ração alimentícia. Por essa razão é que eles procuraram justificar que traços de cobre devem

\footnotetext{
${ }^{\wp}$ Artigo publicado no Arquivos de Biologia e Tecnologia, v. 1, pp. 3-18, 1946.
} 
sempre ser adicionados ao ferro ministrado no tratamento da anemia.

ECHAVE (1941), procurando comprovar os trabalhos anteriores, realizou uma série de provas de laboratório, afim de poder verificar a evidência do cobre na cura de cobáios anemiados, chegando a conclusões muito positivas. Assim é que uma série de cobáios previamente anemiados, cuja contagem globular foi feita, foi submetida a um tratamento com citrato de ferro puro. Por sua vez, outra série de cobáios anemiados, devidamente controlados, foi submetida ao tratamento com citrato de ferro, contendo vestígios de cobre. E o resultado foi ponderável. Com efeito, aqueles animais anemiados que receberam além do ferro, traços de cobre, tiveram com relação aos outros, um aumento sensível de hemoglobina e glóbulos vermelhos, bem demonstrando o papel desempenhado pelo cobre na fixação do ferro.

BERTRAND (1920), analisando uma infinidade de alimentos vegetais e animais, e tendo encontrado cobre em todos eles, estabeleceu por este fato a "necessidade do homem pelo cobre". Continuando, procurou verificar a presença desse elemento, agora nos diversos órgãos do homem, tendo sempre evidenciada a sua presença.

Daí ECHAVE (1941) assegurar que "hoje podemos afirmar de maneira concludente que este metal tão amplamente espalhado pela natureza sob forma inorgânica, é elemento normal sob a forma organizada em todo organismo vegetal e animal, devendo encontrar-se em conseqüência, nos meios onde os ditos organismos se desenvolvem, isto é, na terra, na água, o que a análise tem sempre comprovado".

Atualmente, investigadores americanos tem trabalhado muito no assunto, afim de fornecer os resultados analíticos regionais os mais completos, para que, principalmente os dietéticos, possam buscar as fontes de cura ou pelo menos de preservação da anemia.

LINDOW, ELVEHJEM e PETERSON, analisando 160 alimentos diferentes, encontraram o cobre em todos eles, num teor que variou de 0,1 a 0,44 g por quilo.

Para termos uma idéia do cobre presente nos diversos alimentos vejamos a tabela abaixo, organizada por ECHAVE (1941):
$\mathrm{Cu}, \mathrm{ppm}$. na substância seca

\begin{tabular}{lccc}
\hline Alimento & Argentina & Estados Unidos \\
\hline Aveia & 1,02 & 1,20 \\
Banana & 0,85 & 0,35 \\
Cenoura & 0,70 & 0,93 \\
Figo & 0,62 & 0,50 \\
Laranja & 0,67 & - \\
Alface & 1,56 & - \\
Maçã & 0,72 & 0,60 \\
Pêra & 0,39 & 0,50 \\
Tomate & 0,89 & 1,05 \\
Trigo & 0,77 & 0,87 \\
\hline
\end{tabular}

Nos nossos laboratórios também tivemos a oportunidade de conhecer o teor de cobre nos principais alimentos, cujo resultado analítico podemos encontrar na tabela abaixo:

$\mathrm{Cu}$, ppm. na substância seca

\begin{tabular}{lllll}
\hline \multicolumn{2}{c}{ Alimento } & & \multicolumn{2}{c}{ Alimento } \\
\cline { 1 - 2 } \cline { 5 - 5 } Abóbora & 0,16 & & Lentilha & 1,15 \\
Agrião & 0,85 & & Laranja & 0,15 \\
Alface & 0,30 & & Laranja & 0,66 \\
Alcachofra & 0,86 & & Mamão & 0,04 \\
Amendoim & 0,90 & & Milho & 0,90 \\
Arroz & 0,40 & & Mimosa & 0,57 \\
Alho & 0,60 & & Morango & 1,01 \\
Batata & 0,40 & & Nabo & 0,05 \\
Banana & 0,10 & & Soja & 0,76 \\
Beterraba & 0,59 & & Tomate & 0,50 \\
Cebola & 0,12 & & Tomate & $6,30^{*}$ \\
Cenoura & 0,40 & & Trigo & 0,80 \\
Ervilha & 0,86 & & Cevada & 0,70 \\
Feijão preto & 0,70 & & Centeio & 0,86 \\
\hline * O referido tomate foi & colhido num solo ao qual foi & \\
adicionado cobre. & & \multicolumn{2}{c}{}
\end{tabular}

Nos solos, tanto entre nós como na Argentina, a maioria deles contém o referido elemento. Deve-se anotar desde já, que às vezes o teor encontrado é tão pequeno, que parece estar muito afastado de uma média normal que o solo deveria conter. Com efeito, de acordo com trabalhos por nós realizados (SPITZNER, 1943), tivemos a oportunidade de conhecer os solos que menor teor continham, bem como os mais ricos, e também nos foi possível observar a reação quanto a produtividade, quando naqueles solos pobres em cobre esse elemento era adicionado.

Para dar uma idéia dos teores encontrados, vejamos a seguinte tabela, que apresenta algumas das centenas de análises nossas. 


\begin{tabular}{|c|c|c|c|}
\hline \multicolumn{4}{|c|}{$\mathrm{Cu}, \mathrm{ppm}$. (total) } \\
\hline \multicolumn{2}{|c|}{ Amostra } & \multicolumn{2}{|c|}{ Amostra } \\
\hline 1 & 3,52 & 16 & 0,40 \\
\hline 2 & 3,63 & 17 & 2,12 \\
\hline 3 & 3,47 & 18 & 0,08 \\
\hline 4 & 3,08 & 19 & 0,04 \\
\hline 5 & 1,16 & 20 & 7,60 \\
\hline 6 & 1,27 & 21 & 2,15 \\
\hline 7 & 1,90 & 22 & 5,60 \\
\hline 8 & 0,30 & 23 & 2,16 \\
\hline 9 & 0,26 & 24 & 5,60 \\
\hline 10 & 0,55 & 25 & 1,80 \\
\hline 11 & 3,63 & 26 & 4,90 \\
\hline 12 & 4,80 & 27 & 4,37 \\
\hline 13 & 1,52 & 28 & 4,43 \\
\hline 14 & 1,16 & 29 & 1,39 \\
\hline 15 & 2,88 & 30 & 1,88 \\
\hline
\end{tabular}

Uma análise por nós encontrada em literatura de um solo de La Plata, Argentina, deu um resultado de 23 ppm.

No reino animal, após as pesquisas prévias dos cientistas citados no início deste, muitas análises quantitativas de cobre, muitas observações de eficiência foram feitas, e vejamos algumas delas.

Inúmeros investigadores procuraram verificar o conteúdo de cobre nas diversas partes do nosso corpo. E os resultados foram muito interessantes. Com relação ao sangue, por exemplo, ECHAVE (1941) apresenta o seguinte quadro:

Cobre contido nas diferentes partes do sangue $100 \mathrm{ml}$ de sangue desfibrinado $\quad 0,054 \mathrm{ppm}$. $100 \mathrm{ml}$ de glóbulos $\quad 0,043 \mathrm{ppm}$. $100 \mathrm{ml}$ de soro sanguíneo $\quad 0,014 \mathrm{ppm}$. $100 \mathrm{ml}$ de glóbulos lavados $\quad 0,032 \mathrm{ppm}$. Soro de $100 \mathrm{ml}$ de glóbulos lavados $\quad 0,017 \mathrm{ppm}$.

Conforme era de se esperar, na anemia, geralmente, resultados sensivelmente menores são encontrados. Da mesma forma, em geral, na maioria das doenças contagiosas, o teor de cobre decresce.

Assim, na tuberculose, encontrou-se no pulmão doente, como média, um teor cerca de 10 vezes menor de cobre que no pulmão normal.

Interessante é o quadro ainda organizado por ECHAVE (1941), a respeito do teor de cobre nas diversas enfermidades:

$\begin{array}{lc}\text { Enfermidade } & \text { Cu, total no sangue } \\ \text { Anemia } & 0,127 \mathrm{ppm} . \\ \text { Uremia } & 0,132 \mathrm{ppm} . \\ \text { Anemia } & 0,110 \mathrm{ppm} . \\ \text { Uremia } & 0,131 \mathrm{ppm} . \\ \text { Sífilis } & 0,108 \mathrm{ppm} . \\ \text { Nefrite } & 0,106 \mathrm{ppm} . \\ \text { Sífilis } & 0,131 \mathrm{ppm} .\end{array}$

O cérebro do homem, segundo BODANSKY (1931) confirmando as análises de Thudichunis, acusou um teor que variou de 3,6 a 6 ppm.

TOMPSETT (1935) encontrou uma média de 4 ppm.

Nós encontramos num cérebro adulto, um teor igual a 3,6 ppm.

BUCHNARD e HUDSON acharam nos cérebros de rata um teor igual a 10,4 ppm.

Sob a orientação do prof. Dr. Soler, iniciou-se ao conhecimento do teor de cobre no baço dos diversos animais. $\mathrm{O}$ resultado digno de nota foi o seguinte:

\begin{tabular}{lc}
\multicolumn{1}{c}{ Espécie animal } & Cu, ppm. \\
Rã & 0,78 \\
Galinha & 0,54 \\
Cão & 0,81 \\
Bezerro & 0,71 \\
Porco & 0,92
\end{tabular}

Sobre o conteúdo em cobre em alguns órgãos de cobáio, LINCOLN, PETERSON e STEENBOCK, encontraram o seguinte resultado:

\begin{tabular}{lc}
\multicolumn{1}{r}{ Órgão } & Cu, ppm. \\
Fígado & 11,42 \\
Pulmão & 6,21 \\
Músculos & 2,00 \\
Baço & 3,41 \\
Sangue & 0,54
\end{tabular}

Nós tivemos a oportunidade de efetuar uma análise em baço de cobaia e o teor encontrado foi de 2,8 ppm.

O leite de vaca apresentou para SUPPLE e BELLIS (1922) resultados muito variáveis, e que ele conclui como sendo devido à maior ou menor riqueza de cobre nos alimentos ingeridos, correspondendo diretamente no leite. Observação muito interessante esta, porquanto vem confirmar as nossas observações de enriquecimento de cobre ns alimentos mediante adubação do solo com cobre. $\mathrm{O}$ resultado daqueles autores foi de 0,2 a $0,8 \mathrm{ppm}$. 
Leite de ovelha e de gata apresentam teor de cobre idêntico ao da vaca. Ao contrário, o leite de cabra, sempre acusa um teor menor de cobre. Quanto ao cobre nos tecidos podemos assegurar que segundo autores este não varia de tecido normal para patológico. Sobre o leite da mulher, AVELICH e SERCENKO (1936) encontraram uma grande variabilidade de cobre.

As máximas encontradas foram 0,07 ppm., enquanto que antes do parto esse resultado era cerca de 10 vezes maior.

Os resultados encontrados foram sempre mais ou menos idênticos sendo ora um pouco maior que outro. WHITE (1921) estudando a presença do cobre nos tumores e tecidos normais adjacentes encontrou resultados, sem distinção, que variavam de 7,5 para $12 \mathrm{ppm}$.

GUERITHAULT (1927) chegou a idênticos resultados.

Os animais marinhos apresentam um teor de cobre muito interessante, devidos a ECHAVER (1941). As ostras apresentam um teor igual a $45 \mathrm{ppm}$. enquanto que os camarões 12 ppm., os caranguejos $5 \mathrm{ppm}$. e finalmente os peixes em geral $3 \mathrm{ppm}$.

Pelo exposto, verificamos que as águas destinadas à alimentação não foram estudadas pelos autores que tivemos em mão. E todos devem concordar que sendo a água potável ou mineral um alimento quotidiano, o conhecimento do seu teor de cobre é indispensável, principalmente, sob o ponto de vista dietético. Ainda mais, que o atual Código Brasileiro de Águas recomenda estudos os mais acurados possíveis das águas, atendendo o conhecimento de suas verdadeiras propriedades.

$\mathrm{O}$ que desde já podemos afirmai, é que pelas análises por nós procedidas, encontramos uma variabilidade muito grande no teor em cobre. As águas em contato com as rochas e solos, carregadas de gases e auxiliadas por outros fatores, dissolvem certa quantidade de cobre desses solos ou rochas.

Sabendo-se que um excesso é tão prejudicial ao homem como a deficiência, só uma determinação quantitativa, é que nos poderá colocar a par do valor dietético em cobre, de uma água destinada ao uso.

Baseados em literatura especializada (MASON; BUSWELL, 1931), sabemos que uma quantidade superior a $0,2 \mathrm{ppm}$. é prejudicial ao homem.

A propósito, água com um teor superior àquela máxima já referida, foi por nós encontrada no Município de Guarapuava, conforme análise anexa no fim do presente.
Conhecer, portanto uma quantidade mínima de cobre numa água, é tão importante quanto saber qual o máximo permitido, de maneira a satisfazer o metabolismo do homem em condições normais. Aliás, nos Estados Unidos já estão procurando preestabelecer um mínimo, abaixo do qual considera-se deficiência, uma vez que o máximo já está conhecido.

Nas águas engarrafadas e gaseificadas esse máximo de cobre, em geral advindo de águas que circulam em rochas cupríferas, também pode vir da falta de higiene no engarrafamento, pois este é em geral feito em aparelhagem de cobre, o qual é levemente atacado pelas águas carregadas por gás carbônico. Aliás, no fim do presente, apresentamos um resultado de uma água natural e da mesma após engarrafamento, podendo-se notar o acréscimo em cobre devido à instalação, tratandose de uma indústria que trabalha com muito escrúpulo e muita higiene, bem pode-se avaliar que quantidade de cobre poderia alcançar uma água se as condições de higiene não forem observadas.

Esses fatos bem demonstram a necessidade de conhecer, sistematicamente, o teor de cobre das nossas águas minerais e potáveis, com a dupla finalidade, a de conhecer sob o ponto de vista puramente químico e de fiscalizar sob o ponto de vista higiênico.

Assim, o que se nos deparou a princípio, foi a elaboração de um processo que além da condição essencial da eficiência, fosse relativamente rápido, permitindo trabalhos em série.

Por esta razão, procuramos adaptar um processo já por nós estudado, o da reação entre o cobre e o dietilditiocarbamato de sódio.

Passemos então agora a estudar o comportamento da reação.

$\mathrm{O}$ dietilditiocarbamato de sódio produz uma coloração amarelo-bronzeada com os sais de cobre, formando o dietilditiocarbamato de cobre, conforme a reação:

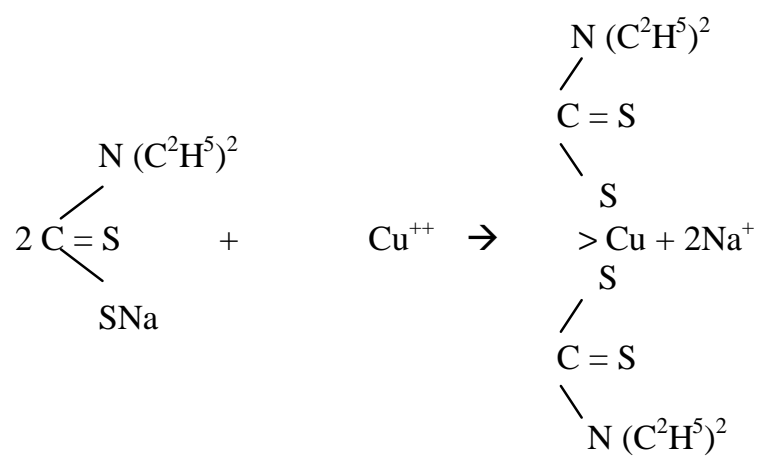


É uma reação citada no Scott Standard Methods of Chemical Analysis.

Sua sensibilidade é muito grande, indo além de $0,002 \mathrm{ppm}$. O dietilditiocarbamato de cobre formado é extraído por meio de um solvente, no caso - o álcool amílico, em volume conhecido, e a solução examinada no fotômetro.

Dentro de certos limites, ela obedece à lei de Beer. Pequenas quantidades de zinco, manganês, cobalto e chumbo, não interferem.

No decorrer das nossas pesquisas, verificamos que, quantidades pequenas de cálcio e magnésio, normalmente existentes nas águas, também não interferem. Daí tratar-se de uma reação de grande segurança.

\section{PREPARAÇÃO DA CURVA PADRÃo}

a) Reativos necessários:

1. Dietilditiocarbamato de sódio, solução a $0,1 \%$ em água. Guardada no escuro. Sua durabilidade é de no máximo uma semana.

2. Ácido cítrico a $50 \%$ em água.

3. Amoníaco concentrado p. a.

4. Álcool amílico.

5. Solução stock de cloreto cúprico em água: dissolver completando, em $1000 \mathrm{ml} \mathrm{de}$ água contendo $20 \mathrm{ml}$ de $\mathrm{HC} 1$ p. a., 0,0269 $\mathrm{g}$ de cloreto cúprico cristalizado. Assim temos uma solução contendo $0,00001 \mathrm{~g}$ por $\mathrm{ml}$, o que corresponde a $0,01 \mathrm{ppm}$. de $\mathrm{Cu}$.

b) Material necessário:

1. Tubos de ensaio $15 \times 200 \mathrm{~mm}$.

2. Tubos de ensaio $10 \times 100 \mathrm{~mm}$.

3. Provetas graduadas de $100 \mathrm{ml} \mathrm{e} 5 \mathrm{ml}$.

4. Pipetas aferidas, pipetas graduadas ao décimo, com capacidade de $1 \mathrm{ml}, 5 \mathrm{ml}$ e $10 \mathrm{ml}$.

5. Funis pequenos.

6. Papel de filtro, diâmetro $4 \mathrm{~cm}$.

7. Centrifugador.

8. Tubos centrifugadores.

A cuba para a leitura é de $10 \mathrm{~mm}$, e foi devidamente eleita.

O filtro usado, S 53, já foi por nós aconselhado no Boletim $n^{\circ} 10$ do I. B. P. T.

\section{TÉCNICA}

Tomamos 6 tubos de ensaio $15 \times 200 \mathrm{~mm}$ com tampa, e colocamos em cada um, a quantidade de cobre, de acordo com o quadro abaixo:

\begin{tabular}{c|c|c|c|c}
\hline Copo & $\begin{array}{c}\text { Ml sol. } \\
\text { estoque }\end{array}$ & $\begin{array}{c}\text { Ml água } \\
\text { bidestilada }\end{array}$ & $\begin{array}{c}\mathrm{Cu} \\
\text { existente }\end{array}$ & ppm \\
\hline 1 & 1 & 9 & 0,00001 & 0,01 \\
2 & 3 & 7 & 0,00003 & 0,03 \\
3 & 5 & 5 & 0,00005 & 0,05 \\
4 & 7 & 3 & 0,00007 & 0,07 \\
5 & 10 & 0 & 0,00010 & 0,10 \\
6 & - & 10 & - & - \\
\hline
\end{tabular}

NOTA: O tubo 6 serve como prova em branco.

Em cada tubo, após agitação, colocamos: 5 gotas de ácido clorídrico concentrado, $2 \mathrm{ml}$ de ácido cítrico e $4 \mathrm{ml}$ de amoníaco. Agitamos energicamente, e deixamos repousar uns 10 minutos.

Pipetamos para um tubo de centrifugação, centrifugamos para a eliminação das gotículas de água em suspensão no álcool, e filtramos com papel seco. Recolhemos em tubo de ensaio $(10 \mathrm{x}$ 100) seco, passamos para a cuba de $10 \mathrm{~mm}$ do fotômetro, para a leitura.

\section{LEITURAS FOTOMÉTRICAS DAS QUANTIDADES DE COBRE}

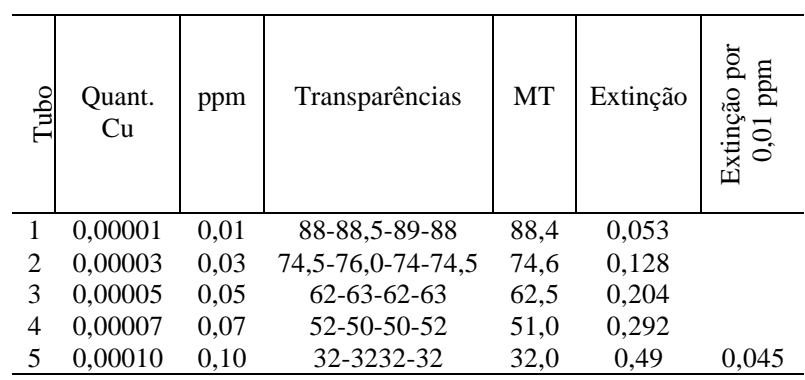

As determinações foram repetidas muitas vezes no presente quadro.

Desta média calculamos o fator 0,219.

Portanto:

Cobre em ppm $=0,219 \mathrm{E}$. 


\section{CONTROLE DAMARCHA ANALÍTICA DO PROCESSO, USANDO QUANTIDADES CONHECIDAS DE COBRE}

Tomamos 5 copos, e em cada um colocamos respectivamente as seguintes quantidades de cobre:

\begin{tabular}{c|ccccc}
\hline Copo & $\begin{array}{c}\text { Quantidade de água } \\
\text { bidestilada }\end{array}$ & $\begin{array}{c}\text { Ml sol. } \\
\text { estoque }\end{array}$ & $\begin{array}{c}\mathrm{Cu} \\
\text { existente }\end{array}$ & $\mathrm{ppm}$ \\
\hline 1 & $1250 \mathrm{ml}+5 \mathrm{HC} 1$ & 1,25 & 0,00001 & 0,01 \\
2 & $1250 \mathrm{ml}+5 \mathrm{HC} 1$ & 6,25 & 0,00005 & 0,05 \\
3 & $1250 \mathrm{ml}+5 \mathrm{HC} 1$ & 8,75 & 0,00007 & 0,07 \\
4 & $1250 \mathrm{ml}+5 \mathrm{HC} 1$ & 12,50 & 0,000010 & 0,10 \\
5 & $1250 \mathrm{ml}+5 \mathrm{HC} 1$ & 0 & - & - \\
\hline
\end{tabular}

NOTA: $\mathrm{O}$ copo $\mathrm{n}^{\circ} 5$ é a prova em branco.

A marcha usada para a referida determinação, foi a seguinte:

Evaporamos as soluções preparadas dos copos, assentando-os em chapa elétrica, até que o volume ficasse reduzido a uns $50 \mathrm{ml}$. Passamos então, para uma cápsula de platina ou quartzo, secamos em banho-maria e finalmente na estufa a $120^{\circ} \mathrm{C}$.

Resfriamos em dessecador e juntamos rigorosamente $10 \mathrm{ml}$ de água bidestilada, contendo $10 \%$ de ácido clorídrico p. a.

Com auxílio de bastão de vidro, atritamos as paredes da cápsula, para dissolução mais rápida dos sais solúveis, depois do que filtramos, recebendo a solução em tubo de ensaio. Todo esse material deve estar rigorosamente seco. Tomamos $8 \mathrm{ml}$ da solução, correspondendo a 1 litro de água, e procedemos à reação já indicada. Pelo quadro que segue, podemos comparar o erro analítico.

\begin{tabular}{c|c|c|c}
\hline Copo & $\begin{array}{c}\text { Quant. } \\
\text { adicionada de } \\
\text { cobre por litro }\end{array}$ & $\begin{array}{c}\text { Quant. de } \\
\text { cobre achada } \\
\text { por litro }\end{array}$ & Diferença \\
\hline 1 & 0,00001 & 0,00001 & - \\
2 & 0,00005 & 0,00005 & - \\
3 & 0,00007 & 0,000076 & $+0,000006$ \\
4 & 0,00010 & 0,000097 & $-0,000003$ \\
\hline
\end{tabular}

Pelo resultado acima, nota-se um erro analítico aceitável, principalmente para determinações de tão pequenas quantidades.

Para conhecer a interferência dos sais de cálcio e magnésio, tomamos uma água mineral alcalina em substituição à água bidestilada do quadro acima. A referida água tinha um teor de cobre indosável.

\section{QUADRO DEMONSTRANDO AS DILUIÇÕES FEITAS PARA OBSERVAR INTERFERÊNCIA DOS SAIS DE CÁLCIO E MAGNÉSIO}

\begin{tabular}{c|c|c|c|c}
\hline Copo & $\begin{array}{c}\text { Mililitros de } \\
\text { água alcalino- } \\
\text { terrosa }\end{array}$ & $\begin{array}{c}\text { Quant. } \\
\text { sol. } \\
\text { estoque }\end{array}$ & $\begin{array}{c}\text { Quant. } \\
\text { de Cu } \\
\text { por litro }\end{array}$ & ppm \\
\hline 1 & $1250+10 \mathrm{HC} 1$ & 1,25 & 0,00001 & 0,01 \\
2 & $1250+10 \mathrm{HC} 1$ & 3,75 & 0,00003 & 0,03 \\
3 & $1250+10 \mathrm{HC} 1$ & 6,25 & 0,00005 & 0,05 \\
4 & $1250+10 \mathrm{HC} 1$ & 8,75 & 0,00007 & 0,07 \\
5 & $1250+10 \mathrm{HC} 1$ & 12,50 & 0,00010 & 0,10 \\
6 & $1250+10 \mathrm{HC} 1$ & 0 & - & - \\
\hline
\end{tabular}

Após a leitura fotométrica e calculação pelo fator descriminado, achamos o seguinte resultado:

\begin{tabular}{ccccc}
\hline Copo & Cu adicionado & Cu achado & Diferenças \\
\hline 1 & 0,00001 & 0,0000092 & $-0,0000008$ \\
2 & 0,00003 & 0,000026 & $-0,0000040$ \\
3 & 0,00005 & 0,000050 & - \\
4 & 0,00007 & 0,000072 & $+0,000002$ \\
5 & 0,00010 & 0,000110 & $-0,000010$ \\
\hline
\end{tabular}

Em vista das observações e do comportamento da reação propomos a seguinte marcha analítica para determinação do cobre em águas.

\section{MARCHA ANALÍTICA PARA DETERMINAÇÃO DO COBRE EM ÁGUAS}

Evaporar cuidadosamente $1250 \mathrm{ml}$ da água a analisar, previamente acidulada com $6 \mathrm{ml}$ de ácido clorídrico puro e $3 \mathrm{ml}$ de ácido nítrico p. a. até reduzi-la ao volume de uns $50 \mathrm{ml}$.

Passar para uma cápsula de platina evaporá-la em banho-maria até secura, e desidratá-la na estufa até $120^{\circ} \mathrm{C}$

Resfriá-la cuidadosamente em dessecador com ácido sulfúrico, juntar-lhe rigorosamente $10 \mathrm{ml}$ de água bidestilada previamente acidulada com ácido clorídrico.

Com bastão de vidro, atritar as paredes por alguns minutos, para a dissolução total das substâncias solúveis, e filtrá-la em papel de filtro seco. Recebê-la em tubo de ensaio seco, tomar $8 \mathrm{ml}$ (corresp. a 1 litro d'água) e proceder à reação. 
Teor de cobre encontrado em algumas águas do Estado, pelo método proposto:

1) Alcalino-terrosa Ouro Fino

Município: Campo Largo

Formação geológica: Série Açunguí

Idade da rocha mater: algonquiano

$\mathrm{Cu}$ $.0,016 \mathrm{ppm}$

2) Alcalino-terrosa gaseificada Ouro Fino

$\mathrm{Cu}$ $.0,048 \mathrm{ppm}$

3) Cloro sulfatada Yara

Município: Bandeirantes

Formação geológica: (?)

Idade da rocha mater: (?)

$\mathrm{Cu}$ $.0,007 \mathrm{ppm}$

4) Sulfurosa alcalina Lambedor

Município: Jaguariaíva

Formação geológica: Série Tibagí-Paraná. Intrusão andesítica, provavelmente neotriássica, nos Folhelhos de Ponta Grossa

Idade das rochas circundantes: neo-devoniano $\mathrm{Cu}$ $.0,024 \mathrm{ppm}$

5) Sulfurosa alcalina Dorizon

Município: Malet

Formação geológica: Série Rio do Rasto

Idade da rocha mater: Intrusão diabásica neotriássica, nas camadas areno-argilosas da Série Rio do Rasto. Rético até Liássico

6) alcalina Santa Clara

Município: Guarapuava

Formação geológica: Série S. Bento

Idade da rocha mater: Neo-triássica

$\mathrm{Cu}$ $.0,038 \mathrm{ppm}$

7) Água "Boeiro das febres"

Município: Guarapuava

Formação geológica: Série S. Bento

Idade da rocha mater: Neo-triássica até posttriássica

$\mathrm{Cu}$ $.0,38 \mathrm{ppm}$

8) Água potável Ahú

Município: Curitiba

Formação geológica: Gnais-granitos

Idade da rocha mater: Arqueano

$\mathrm{Cu}$ $.0,016 \mathrm{ppm}$
9) Água potável Monge

Município: Lapa

Formação geológica: Série Itararé

Idade da rocha mater: Arenitos flúvio-glaciais do carbonífero superior

$\mathrm{Cu}$

10) Água de Curitiba

Município (nascente): Piraquara

Formação geológica: granitos

Idade da rocha mater: Post-algonquiano (huroniano)

$\mathrm{Cu}$ $.0,012 \mathrm{ppm}$

\section{REFERÊNCIAS}

ACHARD (1877), Troubles des nutritives. Masson. $521 \mathrm{p}$.

BERTRAND, J. (1920), Bull. Soc. Hyg. Alimentaire, $8: 49$.

BODANSKY, M. (1931), Journal of Biol. Chem., $48: 36$.

CHEVREUL, M. E. (1868), Compt. Rendue Acad. Sciences, 66 : 567.

FLINN e INOUGE (1929), Journal of Biol. Chem., $84: 101$.

GUERITHAULT (1927), Recherches sur la presence de cuivre dans le vegetaux, etc. Paris : Vigot.

MASON e BUSWELL (1931), Examination of water. 6. ed. New York : John Wiley and Sons. p. 212.

MILLON (1848), Dictionaire Physiologique - art. "Cuivre".

SPITZNER, R. (1943), Sobre a dosagem fotométrica do cobre em solos, etc... Bol. do Instituto de Biologia e Pesquisas Tecnológicas, (10).

SARZEAU, M. J. (1830) Journal de Pharmacie e Chimie, $1: 505$.

SUPPLE, G. C. e BELLIS (1922), Journal Dairy Sc., 6 : 5,445 .

TOMPSETT, S. L. (1935), Biochem. Journal, 29 : 480. AVELICHF e SEVCENKO (1936), "Gasop la Gesk".

WADDEL, Steenbock e HART (1929), Journal of Biol. Chem., $84: 115$.

WHITE, P. (1921), The Lancet. P. 701-703.

\section{OBRAS CONSULTADAS}

CALVET, E. (1934), Química general aplicada a la industria. Barcelona : Salvat. v. 2.

ECHAVE, Dionisio (1941), El metal cobre en biologia. Buenos Aires : Ateneu.

RUDOLFS, W. (1941), Principles of sewage treatment. Washington : National Lime Association.

SCOTT, W. (1939), Standard methods of chemical analysis. 5. ed. New York : Van Nostrand. v. 1. 
SUCKERING (1943), The examination of waters and water supplies. 5. ed. Philadelphia : The Blackiston.

TOUPLEIN, F. (1922), Analyse des eaux. Paris : Liège.

THEROUX, E. e MALMANN (1943), Laboratory manual for chemical and bacterial analysis of water and sewage. 3. ed. New York : McGraw Hill. 